\title{
Low T3 Level and Prognosis of Acute Ischemic Stroke: A Comparative Analysis
}

\author{
${ }^{1}$ Hosne Ara Rahman, ${ }^{1}$ Mahbub ur Rahman, ${ }^{1}$ Jasmine Ara Haque, ${ }^{1}$ Samira Sharmin and ${ }^{2}$ Anup Kumar Saha \\ ${ }^{1}$ Institute of Nuclear Medicine and Allied Science, Mitford. \\ 2 Department of Medicine, Sir Sallimullah Medical College Hospital, Mitford.
}

Correspondence Address : Dr. Hosne Ara Rahman, Principal Medical Officer, Institute of Nuclear Medicine and Allied Science, Sir Sallimullah Medical College Campus, Mitford, Dhaka, E-mail: dr_anunmc07@yahoo.com

\begin{abstract}
Objectives: Neuroendocrine profile is significantly altered in acute ischemic stroke. Increasing evidences suggested that low T3 levels immediately following acute ischemic stroke is associated with greater stroke severity, higher mortality rates and poorer functional outcome. The objective of this study was to see the possible association of serum $\mathrm{T} 3$ level with severity of acute ischemic stroke as well as post stroke recovery.

Material \& Methods: It was a prospective cross sectional study. From October 2014 to June 2015 patients with acute ischemic stroke, presented within 48 hours of onset of symptoms having radiologically confirmed cerebral infarct were enrolled in this study. Blood for thyroid hormone estimation was collected within 48 hours of onset of symptom. Neurological impairment and improvement were assessed using National Institute of Health Stroke Scale (NIHSS) score together with modified Rankin Scale (mRS) on admission day and at 4 weeks post stroke follow-up visit.
\end{abstract}

Result: A total 83 patients met all inclusion criteria were studied. Mean age was 63.4 \pm 15.6 years (range 47-79 years). Among eighty three patients 49 (59\%) had normal T3 level and rest $34(41 \%)$ had low T3 level. Mean T3 level was $0.4 \pm$ $0.3 \mathrm{ng} / \mathrm{ml}$ and $1.8 \pm 0.5 \mathrm{ng} / \mathrm{ml}$ in lowT3 and normal T3 level group respectively. Based on NIHSS scores on admission, a much higher portion of patients $\mathbf{( 7 3 . 5 \% )}$ ) belonged to lowT3 level group fell into moderate-to-severe category while majority of patients $(53.0 \%)$ fell into mild category for normal T3 level group. In post stroke follow up, about 63.2 $\%$ patients with normal T3 level showed favorable neurological functional improvement compared to $\mathbf{3 8 . 2 \%}$ having low T3 level $($ Chi square $=4.9, P<0.05)$.

Conclusion: In patients with acute ischemic stroke lower T3 level elevated the risk of poor functional outcome.

Key words: Ischemic stroke, T3, Functional improvement, National Institute of Health Stroke Scale (NIHSS), modified Rankin Scale (mRS)

\section{INTRODUCTION}

In cerebral ischemia endocrine changes of the hypothalamic-pituitary axis were one of the first measurable alterations. The term non thyroidal illness syndrome (NTIS) identified abnormalities in thyroid function test observed in patients with systemic non thyroidal illness. Low serum T3 level with normal T4 and TSH level was the most common hormonal pattern in NTIS (1). In acute stroke among several other prognostic factors, a reduction of serum $\mathrm{T} 3$ level without elevation of TSH appeared to be associated with the severity of stroke and worse clinical outcome. There are several studies addressed the importance of monitoring thyroid functional status after acute stroke $(2,3)$. The objective of this study was to see the possible association of serum T3 level with severity of stroke as well as post stroke recovery.

\section{STUDY POPULATION}

It was a prospective cross sectional study. Between October 2014 to June 2015 a total number of 83 patients with acute ischemic stroke who were admitted in Sir Sallimullah Medical College Hospital (SSMCH) within 48 hours of onset of symptoms and send to INMAS, Mitford for CT scan of brain showing cerebral infarct were enrolled in this study. Exclusion criteria included patient with history of previous thyroid dysfunction, history of liver disease and history of severe renal disease.

\section{METHODS}

Basic and clinical history including demographic data such as age, sex concurrent illness i.e. hypertension, 
diabetes mellitus, hypercholesterolemia, coronary artery disease, medication and smoking habit were taken into account.

Thyroid function was evaluated by measuring serum total T3, T4, and TSH from blood sample collected within 48 hours of onset of symptoms.T3, T4 were measured by radioimmunoassay (RIA) and TSH by immunoradiometric assay (IRMA) method. In our laboratory normal range for T3 was $0.8-2.3 \mathrm{ng} / \mathrm{ml}$, for T4 was $42-135 \mathrm{ng} / \mathrm{ml}$ and for TSH was $0.3-5$ $\mu \mathrm{IU} / \mathrm{ml}$. Based on the thyroid function results we divided the study subjects into two groups with one low T3 level group and other normal T3 level group.

The detailed clinical examination including the severity of stroke on admission was assessed by Medicine department of SSMCH using NIHSS score. Baseline NIHSS scores on admission was divided into 3 categories, mild: NIHSS < 8; moderate: NIHSS 8-14 and severe: $\geq 14$. At 4 weeks post stroke follow-up visit neurological impairment and improvement were assessed using NIHSS score together with modified Rankin Scale (mRS). The mRS was a scale of measuring the disability of post stroke patients. It had a scale of $0-6$, with 0 designated no limitations or symptoms, 5 being severe disability requiring constant care and 6 being dead. Follow up NIHSS score was compared with patient's baseline NIHSS score to assess functional improvement. Favorable outcome was defined if follow up NIHSS score decrease $\geq 2$ compare to baseline score or $\mathrm{mRS} \leq 3$.

\section{STATISTICAL ANALYSIS}

Continuous data are presented as mean, standard deviation and categorical data as percentages. Chisquare test and unpaired t- test was used to determine the association of $\mathrm{T} 3$ levels with acute ischemic stroke severity and post stroke recovery. Statistical analysis was performed using SPSS software version 16. $\mathrm{P}$ value $<0.05$ was considered statistically significant.

\section{RESULTS}

Eighty three patients with available laboratory data and relatively complete neurological assessment met all inclusion criteria were studied. Sixty one $(73.6 \%)$ was male and twenty two (26.4\%) was female. Mean age $63.4 \pm 15.6$ years (range 47-79 years). Patients with low T3 level group were much older than normal T3 level group. Among eighty three patients 49 (59\%) had normal T3 level and rest 34 (41\%) had low T3 level. In low T3 group mean T3 level was 0.4 $\pm 0.3 \mathrm{ng} / \mathrm{ml}$ whereas in normal T3 group mean T3 level was $1.8 \pm 0.5 \mathrm{ng} / \mathrm{ml}$. Mean NIHSS score on admission was $13.8 \pm 5.9$ and $9.7 \pm 5.6$ in low and normal T3 level group respectively. Based on NIHSS scores on admission, a much higher portion of patients $(73.5 \%)$ belonged to low T3 level group fell into moderate-to-severe category while majority of patients $(53.0 \%)$ fell into mild category for normal T3 level group. In post stroke follow up, about 38.2 $\%$ patients with low $\mathrm{T} 3$ level showed favorable neurological functional improvement compared to $63.2 \%$ having normal T3 level ( Chi square $=4.9$, $\mathrm{P}<0.05)$.

Regarding cerebral blood supply territory affected by stroke, there was no significant difference for anterior or posterior circulation involvement between low and normal T3 level groups.

Table 1: Characteristics of acute ischemic stroke patients with low $\mathrm{T} 3$ and normal $\mathrm{T} 3$ group

\begin{tabular}{|lccc|}
\hline & $\begin{array}{c}\text { Low T3 group } \\
(\mathrm{T} 3<0.8 \mathrm{ng} / \mathrm{ml}) \\
\end{array}$ & $\begin{array}{c}\text { Normal T3 group } \\
(1=34\end{array}$ & $\begin{array}{c}\text { P-value } \\
\mathrm{n}=49\end{array}$ \\
& & & \\
\hline Clinical variables & & & \\
Basclinc NIHSS scorc & $13.8 \pm 5.9$ & $9.7 \pm 5.6$ & \\
Distribution of NIHSS score & & & \\
Mild (<8) & $9(26.4 \%)$ & $26(53 \%)$ & $<0.05$ \\
Moderate (8-14) & $13(38.3 \%)$ & $19(38.8 \%)$ & $<0.025$ \\
Scverc $>14$ & $12(35.3 \%)$ & $4(8.2 \%)$ & $<0.125$ \\
\hline Laboratory variable & & & \\
T3 & $0.4 \pm 0.3 \mathrm{ng} / \mathrm{ml}$ & $1.8 \pm 0.8 \mathrm{ng} / \mathrm{ml}$ & \\
T4 & $71.9 \pm 29.5 \mathrm{ng} / \mathrm{ml}$ & $89.5 \pm 31.4 \mathrm{ng} \mathrm{ml}$ & \\
TSH & $1.5 \pm 1.0 \mu \mathrm{IU} / \mathrm{ml}$ & $3.1=1.8 \mu \mathrm{IU} / \mathrm{ml}$ & \\
\hline
\end{tabular}


Table 2: Post stroke outcome assessed by NIHSS and $\mathrm{mRS}$ scale.

\begin{tabular}{|lccc|}
\hline & $\begin{array}{c}\text { Low T3 group } \\
\mathrm{n}=34\end{array}$ & $\begin{array}{c}\text { Normal T3 group P value } \\
\mathrm{n}=49\end{array}$ & \\
\hline Follow up NIHSS score decrease $\geq 2$ & 8 & 19 & \\
Patient with favourable outcome $(\mathrm{mRS} \leq 3)$ & 5 & 12 & \\
\hline Patients with functional improvement & Total $-13(38.2 \%)$ & $31(61.2 \%)$ & $<0.05$ \\
\hline
\end{tabular}

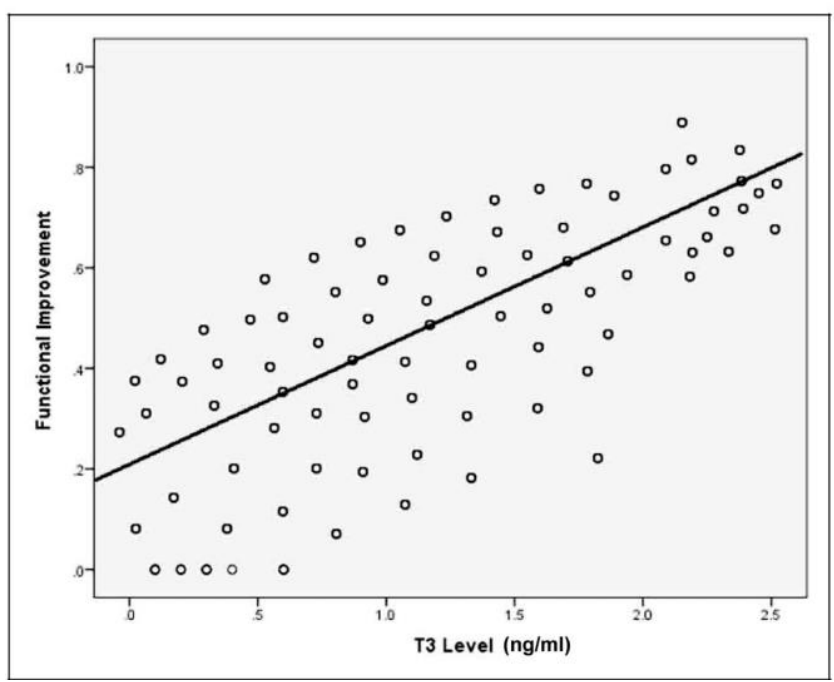

Figure 1. Scatter plot showing the correlation between the serum T3 level (x-axis) and functional improvement (y-axis).

\section{DISCUSSION}

Stroke is a complex disease that required a coordinated care of multidisciplinary team to improve the outcome. The reported prevalence of stroke in Bangladesh was $0.3 \%$. According to a leading tertiary care hospital based study in our country $14.7 \%$ of total admission was stroke patient. It is a leading cause of functional impairment with $20 \%$ survivors requires institutional care for about 3 months and $15-30 \%$ being permanently disabled (4). Early and accurate prediction of outcome in acute stroke is important and influence risk optimized therapeutic strategies. The maximum number of patients in this study were between the age group 5565 years which coincide with some other study done in our country where highest incidence of stroke were between 5 th to 7 th decade of life $(5,6)$. There are several factors that impact on stroke outcome such as age, associated medical condition like hypertension, diabetes mellitus, cardiac problem, hypercholesterolemia, renal disease and multiple organ dysfunctions. In our country Nuclear Medicine department provide thyroid hormone assessment by nuclear technique which is very sensitive, accurate and much established in our health service. Some studies strongly suggested that thyroid hormones have a capacity to exert neuroprotective actions in central nervous system under ischemic condition $(7,8)$. The coexistence of severe disease and low T3 syndrome has gained widespread attention, but the pathophysiological mechanism underlying this phenomenon is still unknown. Possible mechanisms include peripheral thyroid hormone metabolism changes due to alterations in activity of the enzymes responsible for peripheral conversion of $\mathrm{T} 4$ to $\mathrm{T} 3$, pro inflammatory cytokine action involvement, a disturbed shift in the distribution of thyroid hormones or an alteration in binding proteins. Excessive glucocortcoids released in stress condition like acute stroke inhibits the activities of hypothalamic-pituitary-thyroid axis which was also responsible for low T3 level $(9,10)$.

Regarding the association of $\mathrm{T} 3$ level and severity of stroke the present study showed that $73.6 \%$ patients belonged to low T3 group fell into moderate-to-severe category (NIHSS: $8-14$ or $\geq 14$ ) while $53 \%$ patients of normal T3 level group fell into mild category (NIHSS < 8). Neidert et al. in a study showed the same findings where a negative correlation exist between NIHSS score and T3 level $(r=-0.27)$ whereas, T4 level did not correlate with NIHSS score $(r=0.0008)$ They also reported mortality rate within 90 days is $10.7 \%$ among the patients having low T3 level (1). According to Alevizaki et al. annual mortality rate was $27.3 \%$ and $19.3 \%$ in low and normal T3 cases respectively $(\mathrm{p}=0.006)$. Similar finding was reported by Ambrosius et al. regarding NIHSS score, neural damage and annual mortality rate in low fT3 level patients and they concluded that, low T3 level was not only an independent predictor of early and late stage survival, it also predict the severity of disability one year after disease (11).

In present study $61.8 \%$ patients having normal T3 level showed favorable neurological functional 
improvement compared to $38.2 \%$ having lowT3 level $(\mathrm{p}<0.05)$.It reflect positive relation between high T3 level and post stroke recovery $\left(\mathrm{r}^{2}=.001\right)$. This finding was consistent with several other studies performed in acute stroke patients and in intensive care units. According to these studies low T3 or the combination of $\mathrm{T} 3$ and $\mathrm{T} 4$ appeared to be associated with worse prognosis. They also mentioned that the alterations of $\mathrm{T} 3$ levels was related to a disturbance of thyroid hormone metabolism rather than a blood supply related structural disturbance of the hypothalamic-pituitary-thyroid axis $(12,13)$. Guan et al. showed patient with large artery infarction accompanied by low T3 level had severe neural damage leading to worse prognosis (14). Although several studies confirmed that serum T3 level is indeed an independent predictor of post stroke outcome still there are controversies regarding the association between thyroid hormone levels and post stroke recovery $(15,16)$. An experimental data have shown that exogenous T3 administration helped in reducing the size of cerebral infarct and improve neurological deficit but there is still no conclusive answer whether treatment of low T3 level in acute stroke would improve the condition or not (17).

Limitations of the present study include small sample size, single baseline measurement of thyroid function, lack of long-term follow up, other pituitary axis hormone specially the cortisol level and other risk factors affecting the prognosis of stroke were not assessed.

In conclusion it can be said that thyroid dysfunction had a major impact in ischemic stroke. The degree of low T3 level may be one of the useful predictor of assessing functional improvement in patients with acute ischemic stroke.

\section{REFERENCES}

1. Neidert S, Katan M, Schuetz P, Fluri F, Ernst A, Bingisser R . et.al .Anterior Pituitary Axis Hormone and Outcome in Acute Ischemic Stroke. J Intern Med 2011; 269:420-32.

2. Hama S, Kitaoka T. Malnutrition and Nonthyroidal Illness Syndrome after Stroke. Metabolism: Clinical and Experimental 2005; 54 (6):699-701.

3. Alevizaki A, Synetou M, Xynos K, Pappa T, Vemmos KN. Low triiodothyronine: a strong predictor of outcome in acute stroke patients. European Journal of Clinical Investigation 2007; 37 (8):651-657.

4. Siddique MR, Islam QT, Iqba MJ, Binte Mosharraf SS. Socio-demographic Status \& Associated Risk Factors of the Stroke Patient in Tertiary Care Hospital of Bangladesh. AKMMCJ 2013; 4(2):218-24.

5. Hossain AM, Ahmed NU, Rahman M,Islam MR, Sadhya G,Fatema K.Analysis of Sociodemographic and Clinical Factors Associated with Hospitalized Stroke Patients of Bangladesh. Faridpur Med Coll.J 2011;6(1):19-23.

6. Islam N, Moniruzzaman M, Khalil I, Basri R,Alom K,Loo KW,Gan HU.Burden of Stroke in Bangladesh. International Journal of Stroke 2013;8(3):211-13.

7. Oka N, Kashiwagi T, Hatazawa J. Nuclear Neuroimaging in Acute and Subacute Ischemic Stroke. Ann Nucl Med 2010;24(9):629-38.

8. De Groot L J. Dangerous dogmas in medicine: The Nonthyroidal Illness Syndrome. Journal of Clinical Endocrinology and Metabolism 1999; 84(1) 151-64.

9. Bunevicius A, Iervasi G, Bunevicius R. Neuroprotective Actions of Thyroid Hormone and Low-T3 Syndrome as a Biomarker in Acute Cerebrovascular Disorder.Expert Rev Neurother $2015: 15(3): 315-26$.

10. Bianco AC, Salvatore D, Gereben B, Berry MJ, Larsen PR. Biochemistry, Cellular and Molecular Biology and Physiological Roles of the Iodothyronine Selenodeiodinases. Endocrine Reviews2002;23(1): 38-89.

11. Ambrosius W, Kazmierski R, Gupta V, Warot AW, Adamczewska KD, Blazejewska A et al. Low FT3 Levels are Related to Poor Prognosis in Acute Ischemic Stroke. Exp Clin Endocrinol Diabetes 2011; 119:139-43.

12. Park KS, Jeong GC, Cho SG, Jang KS, Kim J,Ha JM. The Effect of Thyroid Hormone Withdrawl on Brain Glucose Metabolism in Differentiated Thyroid Cancer. J Nucl Med 2014; 55:1881-83.

13. Peeters RP, Wouters PJ, Kaptein E, VanToor H, Visser TJ, Van den Berghe G. Reduced Activation and Increased Inactivation of Thyroid Hormone in Tissues of Critically Ill Patients. Journal of Clinical Endocrinology and Metabolism 2003; 88(7):3202-11.

14. Guan-Hui Wu, Fan Zhen K, Qing Zhang C,Wei Feng L, Xiang Dong Du. Low T3 Syndrome Predict Severe Neurological Deficits of Cerebral Infarction in Patients with Large Artery Atherosclerosis in Internal Carotid Artery Syndrome. Neuroendocrinol Lette 2014; 35(2):149-53.

15. Faber J, Kirkegaard C, Rasmussen B. Pituitary-Thyroid Axis in Critical Illness. Journal of Clinical Endocrinology and Metabolism 1987;65(2):315-20.

16. Forti P, Maiol F, Procaccianti G, Nativio V, Lega MV, Coveri M, et al. Independent Predictors of Ischemic Stroke in the Elderly :Prospective data from a stroke unit. Neurology 2013;80:3809-13.

17. Hiroi Y, Kim HH. Rapid Nongenomic Actions of Thyroid Hormone. Proceedings of the National Academy of Sciences of the United States of America 2006 ;103( 38) :14104-09. 